\title{
Estudo da quantidade de jogadores em jogos reduzidos de handebol: mudança na dinâmica técnica e tática
}

CDD. 20.ed. 796.017

796.31
Filipe Manuel CLEMENTE*/**

Rúben Filipe ROCHA ${ }^{* *}$ Rui Sousa MENDES*

\section{Resumo}

0 objetivo do presente estudo foi o de analisar os efeitos de diferentes formas de jogo $(2 \times 2,3 \times 3$ e 4 $x 4$ ) de handebol no desempenho técnico e tático de alunos de Educação Física. Participaram no estudo oito alunos do sexo masculino $(18,25 \pm 1,04$ anos de idade). Os indicadores que apresentaram diferenças significativas foram: contatos na bola, número de passes de ombro, passes de ombro completados e origem de pontos através de ataque organizado e contra-ataque. Conclui-se que as formas de jogo com menor número de alunos aumentaram a quantidade de ações técnicas e táticas, sugerindo-se estas formas numa fase inicial de aprendizagem.

Palavras-chave: Ensino; Educação física; Jogos reduzidos; Handebol.

\section{Introdução}

A Educação Física caracteriza-se por ser uma disciplina escolar que poderá incluir diferentes modelos de ensino que enaltecem, de forma distinta, determinados conteúdos de aprendizagem ${ }^{1}$. De fato, poderão existir distintos modelos de ensino que, apesar de se diferenciaram no processo, procuram atingir o mesmo objetivo. Assim, incumbe-se ao professor de Educação Física adotar modelos de ensino adequados às qualidades e capacidades individuais e características dos alunos da turma ${ }^{2}$.

No seguimento, novos modelos de ensino baseados na manutenção da realidade ecológica do jogo têm captado considerável atenção por parte da investigaçáo em ensino ${ }^{3-5}$. Dos modelos ecológicos, evidenciam-se o Teaching Games for Understanding ${ }^{6}$ e a Pedagogia Não-linear ${ }^{5}$. Tais modelos de ensino enfatizam proeminentemente o comportamento tático defendendo a integridade e desenvolvimento da técnica no contexto complexo e dinâmico do jogo $^{7}$. Neste sentido, os jogos manipulados pelo professor deverão recorrer a constrangimentos $\mathrm{da}$ tarefa $^{8}$ que permitam afinar percetivamente os alunos com os objetivos e conteúdos planeados pelo professor ${ }^{7}$. Desta forma, os constrangimentos da tarefa relacionados com o espaço e número de alunos jogo revelam-se como fundamentais para o desenvolvimento e consecução da aprendizagem ${ }^{9-13}$.

No fundo, os jogos reduzidos apresentam-se como uma constante nos modelos de ensino baseados na ecologia da modalidade ${ }^{2}$, pelo que, o professor deverá considerar de forma reflexiva a implementaçáo dos constrangimentos a utilizar ${ }^{8}$ no sentido de cumprir os conteúdos definidos para a sessão. Consequentemente é essencial analisar de forma sistemática os efeitos do número de jogadores por tarefa no sentido conhecer se existem efeitos no desenvolvimento de açōes técnicas e comportamentos táticos.

Parece consensual admitir que as formas de jogo são fatores preponderantes na ação técnica dos alunos em jogos reduzidos, onde a relação se estabelece como inversa entre o número de jogadores e a frequência de açóes individuais ${ }^{14}$. De fato, adicionando praticantes, o número de ações técnicas total aumentam, no entanto, a frequência técnica individual reduz ${ }^{13}$.

Nesse sentido, o presente estudo teve como objetivo analisar a influência de diferentes formas de jogo $(2 \times 2,3 \times 3$ e $4 \times 4)$ nas açôes técnico/táticas. Face à literatura, é expectável verificar valores superiores de ações técnicas nas formas de jogo mais reduzidas. 


\section{Método}

\section{Participantes}

Participaram do estudo oito alunos do sexo masculino (18,25 $\pm 1,04$ anos de idade) com nível de aptidão elementar (i.e., domina os conteúdos essenciais, mas não é perito) para a modalidade, seguindo a definição do Programa Governamental Português para a disciplina e sem experiência no handebol federado. Os alunos pertenciam a uma turma do $12^{\circ}$ ano de escolaridade em Portugal. Todos os alunos participaram voluntariamente, assinando um termo de consentimento livre e esclarecido. O estudo foi realizado em conformidade com o código de ética da Universidade de Coimbra e as recomendaçóes da Declaração de Helsínque em Pesquisa com Seres Humanos. Os participantes não sofriam de qualquer tipo de incapacidade física ou mental.

\section{Tarefa}

A tarefa consistiu em transportar a bola da zona defensiva até à zona ofensiva da equipe adversária, respeitando os princípios de jogo e regras da modalidade, ultrapassando a linha de baliza adversária através de um passe para um atacante que recebe a bola após a linha de baliza da equipe adversária ("zona de ponto" da sua equipe).

Cada condição de prática decorreu durante cinco minutos, onde o principal objetivo era assumido pela marcação de um ponto por cada transposição válida (i.e., recepção da bola em trajetória aérea por um único elemento da equipe atacante após a linha de baliza da equipe adversária, na zona de ponto da sua equipe).

\section{Instrumentos}

Para a filmagem das ações dos alunos utilizou-se uma câmara digital SLR (Canon EOS 500D) com capacidade para processar imagens a $30 \mathrm{~Hz}$ (i.e., 30 imagens por segundo). Esta foi colocada a 4,53 $\mathrm{m}$ acima do solo, no plano sagital à realização da tarefa. Utilizaram-se bolas regulamentadas pela $\mathrm{Fe}$ deração Portuguesa de Handebol para a faixa etária dos alunos. Coletes azuis e verdes foram utilizados de forma a diferenciar as equipes em confronto. A análise notacional de jogo realizou-se através da visualização posterior das filmagens, recorrendo a documentos de observaçáo concebidos para o efeito. Decorrente da análise notacional, registaram-se os valores totais de açóes por cada jogo. Esses valores foram em seguida utilizados como dados de referência para a computação dos testes estatísticos.

\section{Procedimentos}

O primeiro espaço ( $1 / 8$ do espaço formal) compreendeu uma área de 10 x 7,5 metros e o segundo espaço (2/8 do espaço formal) uma área de 20 x 7,5 metros. Paralelamente à área da linha de baliza, prolongavase em dois metros de comprimento uma área (zona de ponto) que definia a zona de receçáo da bola por parte do atacante. A tarefa decorreu em seis situaçóes distintas, interagindo as formas de jogo $2 \times 2,3 \times 3$ e $4 \times 4$ com os espaços de 1/8 e 2/8 do campo formal.

$\mathrm{Na}$ região superior ao espaço de prática uma câmara digital SLR (Canon EOS 500D) com capacidade para processar imagens a $30 \mathrm{~Hz}$ (i.e., 30 imagens por segundo), registou as tarefas concretizadas pelos alunos.

\section{Procedimentos estatísticos}

Recorreu-se ao teste de análise da variância ANOVA "one-way" para analisar as diferenças entre os fatores " 2 × 2", " 3 × 3" e “4 x 4" em relaçáo às variáveis dependentes selecionadas, pertencentes aos compósitos dos indicadores técnicos e táticos. Apenas o número de alunos por jogo reduzido foi analisado no presente trabalho. Previamente à utilização do teste, analisaram-se a normalidade e homogeneidade da amostra de forma a validar a utilização do teste paramétrico. Sempre que o teste ANOVA "one-way" detetou diferenças estatisticamente significativas, recorreu-se ao teste "post-hoc" de Bonferroni, recomendado para as características específicas do número da amostra. Foi ainda calculada a dimensão do efeito, sendo que a sua interpretação seguiu os valores de referência de Hopkins et al. ${ }^{15}$. As análises estatísticas foram executadas com o "software" SPSS Statistics (versão 20, IBM SPSS, Chicago, IL). Definiu-se um nível de significância de 5\% para todo o tratamento estatísto. 


\section{Resultados}

\section{Indicadores técnicos}

O número de jogadores em cada tarefa poderá constranger as açôes realizadas em campo. Estudos realizados sobre esta temática têm procurado analisar as diferentes formas de jogo com rácios iguais de espaço de prática por jogador. Inversamente, o presente trabalho mantém os espaços definidos para as formas de jogo diferenciadas. Desta forma, procurar-se-á apresentar apenas os resultados estatísticos referentes à diversificação do número de alunos por condição, i.e., quatro alunos na forma de jogo $2 \times 2$, seis alunos na forma de jogo $3 \times 3 \mathrm{e}$ oito alunos na forma de jogo $4 \times 4$ (TABELA 1).

TABELA 1 - Valores de significância para cada indicador técnico analisado.

\begin{tabular}{|c|c|c|}
\hline Indicador & Valor de $F$ & p-value \\
\hline Contatos na bola & 11,465 & $0,039^{*}$ \\
\hline Fintas & 1,233 & 0,407 \\
\hline Pontos marcados em cada jogo & 0,091 & 0,916 \\
\hline Interceçôes de bola & 0,073 & 0,931 \\
\hline Recuperaçóes de bola & 11,400 & $0,040^{*}$ \\
\hline Total de passes efetuados & 8,683 & 0,057 \\
\hline Número de passes completados & 7,008 & 0,074 \\
\hline Número de passes incompletos & 0,245 & 0,797 \\
\hline Número de passes de peito & 1,000 & 0,465 \\
\hline Número de passes de peito & 1,000 & 0,465 \\
\hline Número de passes de ombro & 142,956 & $0,001^{*}$ \\
\hline Número de passes de ombro completados & 477,100 & $0,001^{*}$ \\
\hline Número de passes de ombro incompletos & 7,588 & 0,067 \\
\hline Número de passes picados & 12,034 & $0,037^{*}$ \\
\hline Número de passes picados completados & 8,652 & 0,057 \\
\hline Número de passes picados incompletos & 4,939 & 0,112 \\
\hline Número de outros tipos de passes & 1,970 & 0,284 \\
\hline Número de outros tipos de passes completados & 1,453 & 0,362 \\
\hline Número de outros tipos de passes incompletos & 1,235 & 0,406 \\
\hline
\end{tabular}

Os gráficos que se seguem (FIGURAS 1, 2, 3 e 4) foram construídos a partir da frequência absoluta das açôes técnicas e percentagem em função do número total em outros casos. De forma a simplificar a exposição dos resultados, apenas se procedeu ao destaque dos valores com significado estatístico. 

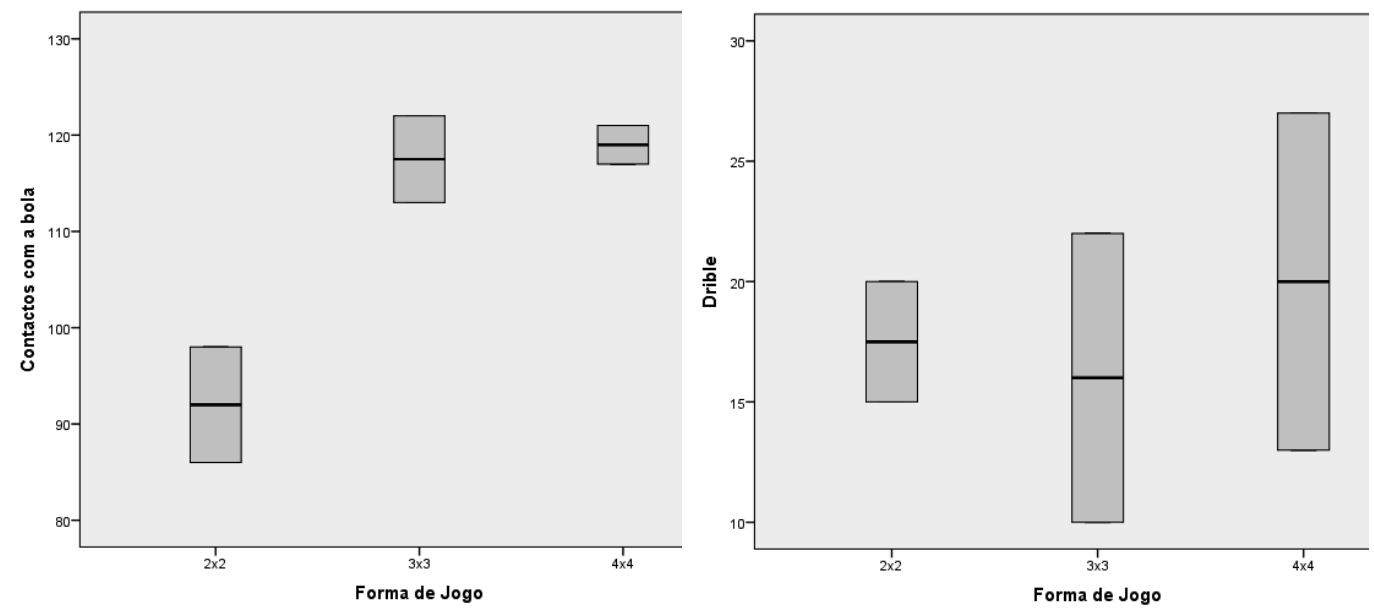

FIGURA 1 - Indicadores técnicos ofensivos (contactos na bola e drible).

Considerando o indicador contatos na bola foi possível identificar diferenças estatisticamente significativas, com efeito elevado $\left(F_{(2,3)}=11,465\right.$;

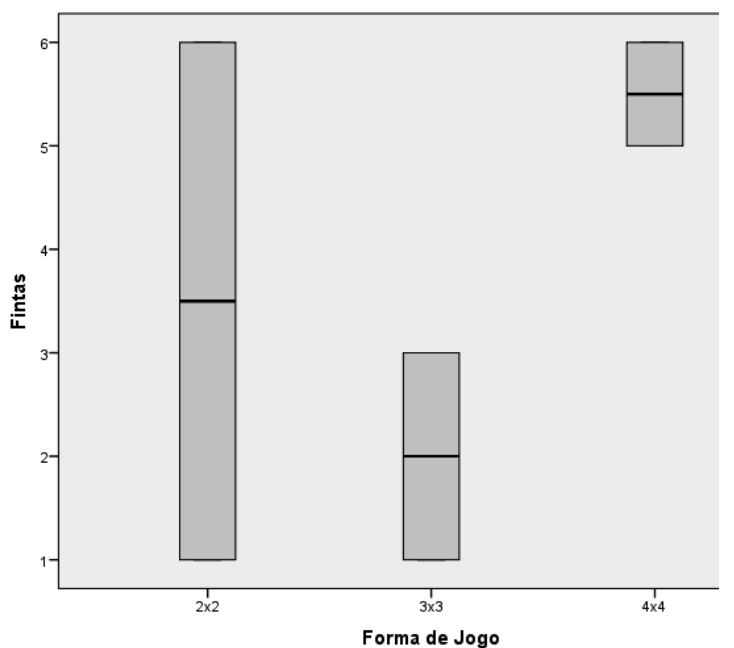

"p-value" = 0,039; "Effect Size" = 0,884). De fato, a maior quantidade média surge na forma de jogo $4 \mathrm{x}$ 4 sendo que, o inverso sucede na forma de jogo $2 \times 2$.

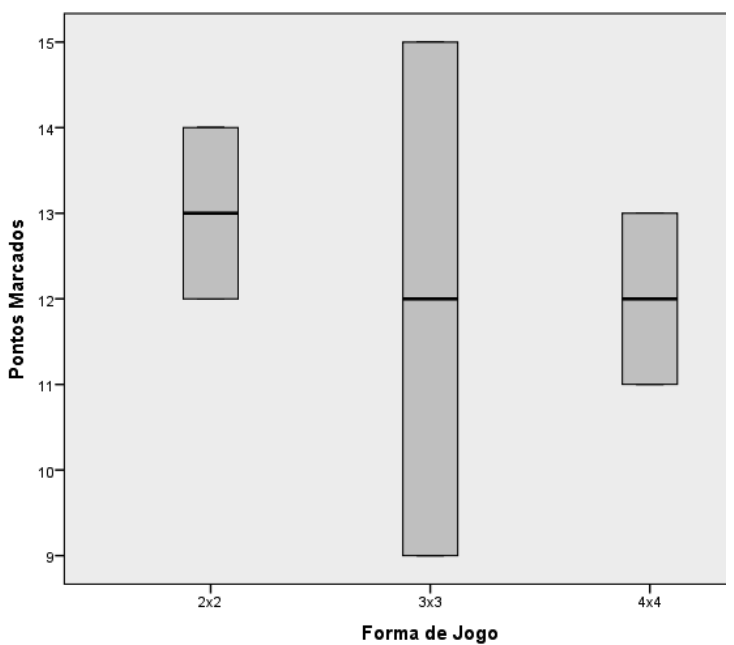

FIGURA 2 - Indicadores técnicos ofensivos (fintas e pontos).

No que concerne ao indicador recuperaçóes de bola verificaram-se diferenças estatisticamente significativas com efeito elevado $\left(F_{(2,3)}=11,400\right.$; "p-value" = 0,040; “Effect Size" = 0,884). De fato, a maior quantidade média surge na forma de jogo $3 \mathrm{x}$ 3 sendo que, o inverso sucede na forma de jogo $2 \times 2$. 

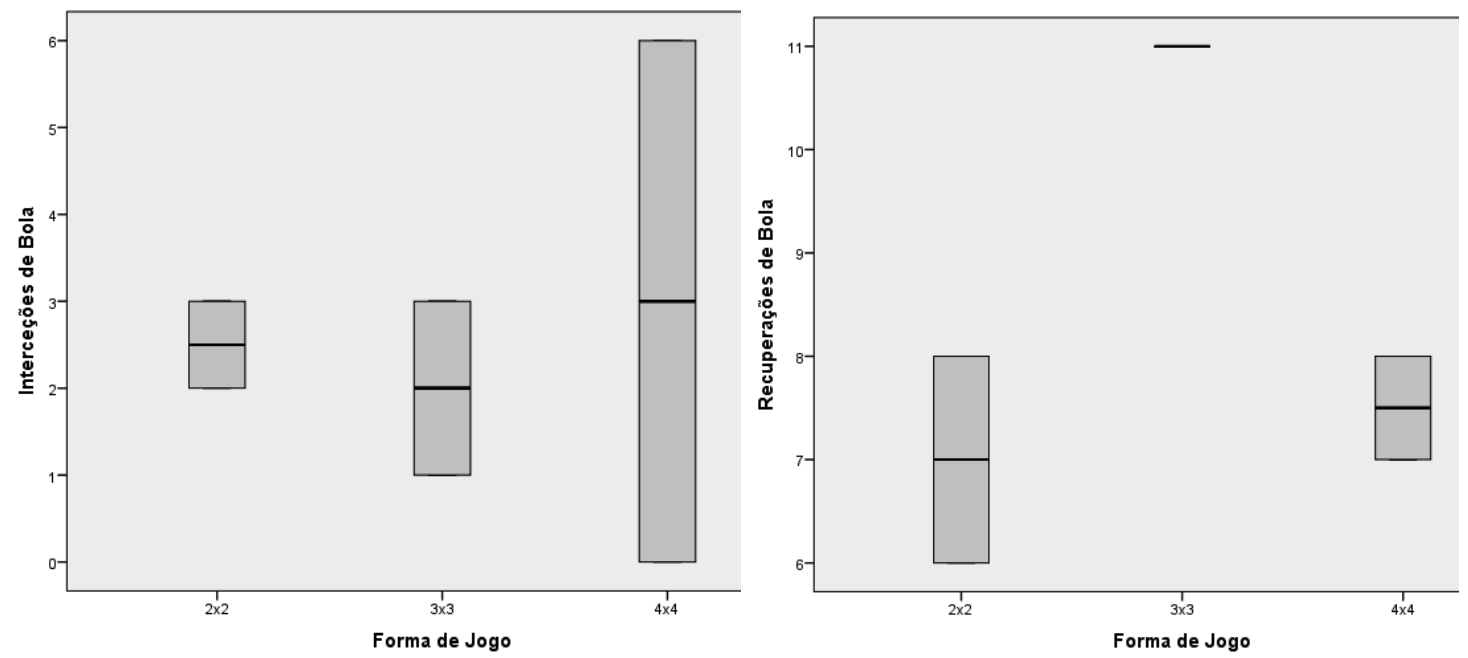

FIGURA 3 - Indicadores técnicos defensivos (interceções e recuperações).

No que concerne ao indicador número de passes de ombro verificaram-se diferenças estatisticamente significativas, com efeito elevado $\left(F_{(2,3)}=142,956\right.$; "p-value" = 0,001; "Effect Size" = 0.990). De fato, a maior quantidade média surge na forma de jogo $4 \mathrm{x}$ 4 sendo que, o inverso sucede na forma de jogo $2 \times 2$.

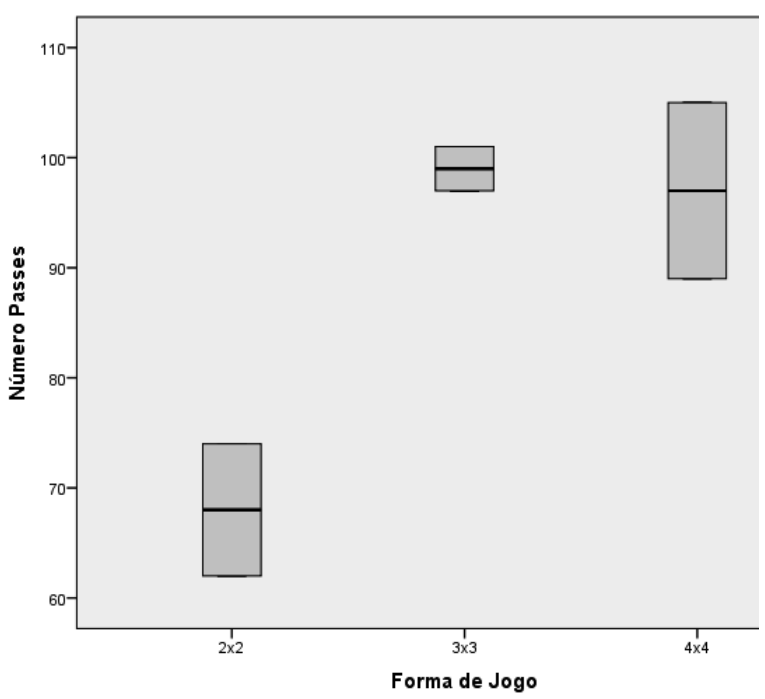

FIGURA 4 -Indicadores técnicos ofensivos (passes).

Quanto ao indicador número de passes de ombro completados verificaram-se diferenças estatisticamente significativas com efeito muito elevado $\left(F_{(2,3)}\right.$ = 477,100; "p-value" < 0,001; "Effect Size" = 0,997). De fato, a maior quantidade média surge na forma de jogo 4 x 4 sendo que, o inverso sucede na forma de jogo $2 \times 2$.

Considerando o indicador número de passes picados, existem evidências estatísticas para se afirmar que as médias analisadas se diferenciam significativamente com efeito muito elevado $\left(F_{(2,3)}=12,034\right.$; "p-value" = 0,037; "Effect Size" = 0,889). De fato, a maior quantidade média surge na forma de jogo $2 \mathrm{x}$ 2 sendo que, o inverso sucede na forma de jogo $4 \times 4$.

\section{Indicadores táticos}

As formas de jogo implementadas durante a sessão de exercitação poderão repercutir-se em variaçóes inerentes a processos táticos dos alunos. Nesse sentido, considerar-se-ão possíveis variâncias entre as formas de jogo utilizadas no que se refere a indicadores táticos que sustentam o processo de desenvolvimento coletivo dos alunos. 
TABELA 2 - Valores de significância para cada indicador técnico analisado.

* diferenças entre médias com valor significativo para um $p$-value $\leq 0,05$.

\begin{tabular}{lcc}
\hline Indicador & Valor de $\boldsymbol{F}$ & p-value \\
\hline Número de ataques & 0,057 & 0,945 \\
Número de ataques organizados & 0,034 & 0,966 \\
Número de ataques organizados com gol & 0,086 & 0,920 \\
Número de ataques organizados sem gol & 0,655 & 0,581 \\
Número de contra-ataques & 6,500 & 0,081 \\
Número de contra-ataques sem gol & 24,500 & $0,014^{*}$ \\
Origem de pontos através de ataque organizado & 11,882 & $0,038^{*}$ \\
Indicador origem de pontos através de contra-ataque & 11,882 & $0,038^{*}$ \\
Eficácia do ataque organizado & 0,496 & 0,652 \\
Eficácia do contra-ataque & 36,987 & $0,008^{*}$ \\
Marcaçóes individuais & 3,657 & 0,157 \\
Desmarcações & 16,661 & $0,024^{*}$ \\
\hline
\end{tabular}

A TABELA 2 indica os valores de significância alcançados através dos testes estatísticos de análise da variância para cada indicador analisado. As
FIGURAS 5, 6 e 7 apresentam os quartis de açóes táticas realizadas nas distintas formas de jogo.

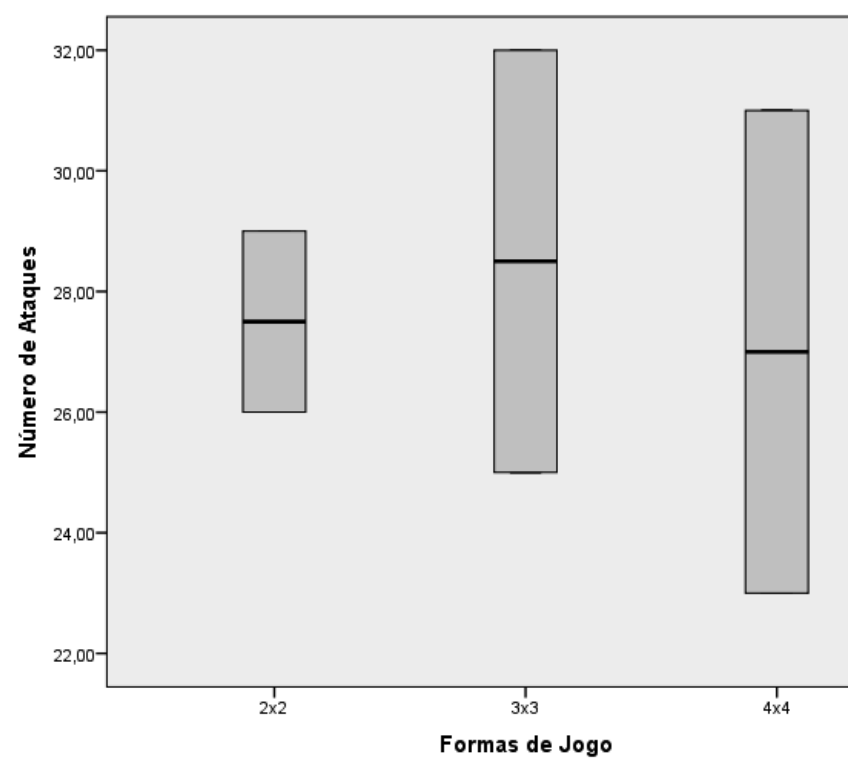

FIGURA 5 - Quantidade de ataques.

No que se refere ao indicador número de contra-ataques sem gol verificaram-se diferenças estatisticamente significativas, com efeito elevado $\left(F_{(2,3)}=24,500\right.$; “p-value" $=0,014$; "Effect Size" = $1,000)$. De fato constata-se que a maior frequência média surge na forma de jogo $2 \times 2$ sendo que, o inverso sucede na forma de jogo $3 \times 3$, diferenciandose entre si (“p-value” =0,014).
Quanto ao indicador origem de pontos através de ataque organizado verificaram-se diferenças estatisticamente significativas com efeito muito elevado $\left(F_{(2,3)}=11,882\right.$; “p-value" = 0,038; "Effect Size" = $0,888)$. De fato constata-se que a maior frequência média surge na forma de jogo $3 \times 3$ sendo que, o inverso sucede na forma de jogo $2 \times 2$, diferenciandose entre si (“p-value” $=0,038)$. 
No que se refere ao indicador origem de pontos através de contra-ataque verificaram-se diferenças estatisticamente significativas com efeito muito elevado $\left(F_{(2,3)}=11,882\right.$; “p-value” $=0,038$; “Effect

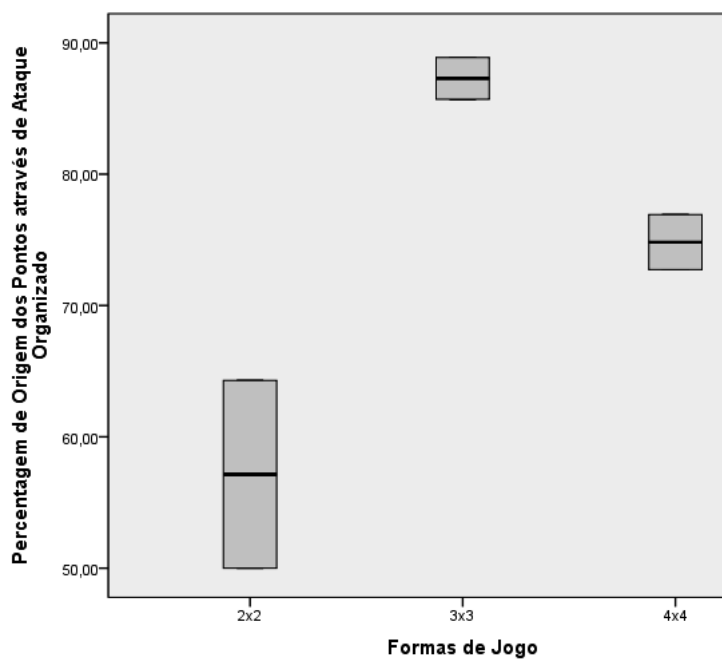

Size” $=0,888)$. De fato constata-se que a maior frequência média surge na forma de jogo $2 \times 2$ sendo que, o inverso sucede na forma de jogo 3 x 3, diferenciando-se entre si (“p-value" = 0,038).

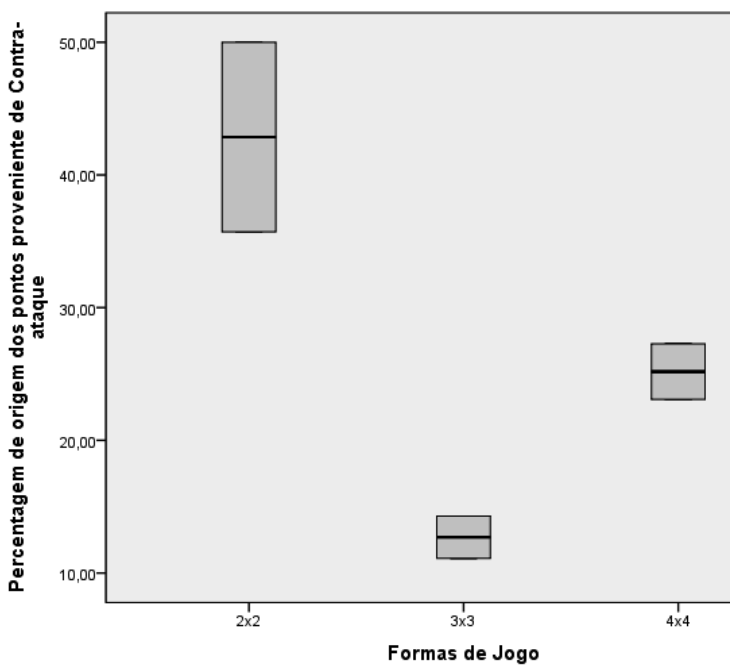

FIGURA 6 - Origem dos pontos (Ataque organizado e contra-ataque).

Perspetivando o indicador eficácia do contraataque verificaram-se diferenças estatisticamente significativas, com efeito elevado $\left(F_{(2,3)}=36,987\right.$; "p-value" = 0,008; "Effect Size" = 0,961).

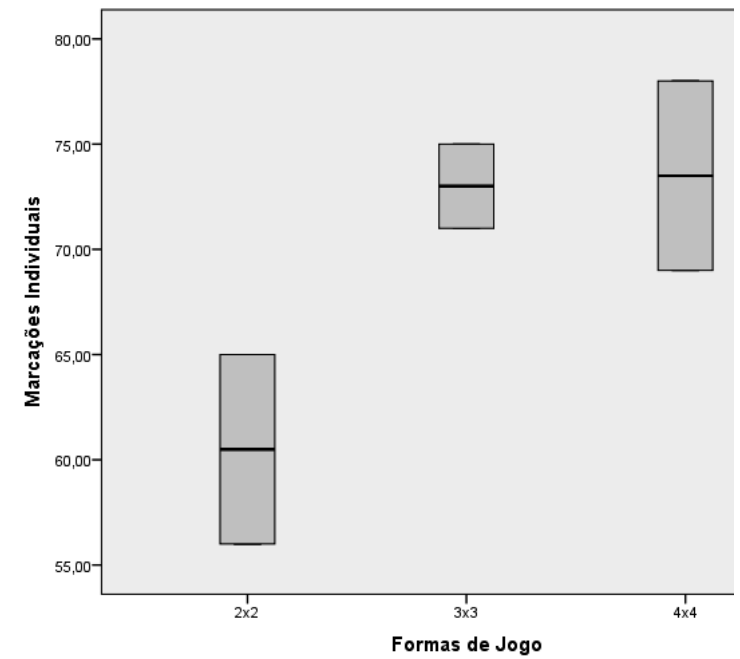

Especificamente, constata-se que a maior frequência média surge na forma de jogo $2 \times 2$ sendo que, o inverso sucede na forma de jogo $3 \times 3$, diferenciandose entre si ("p-value” =0,008).

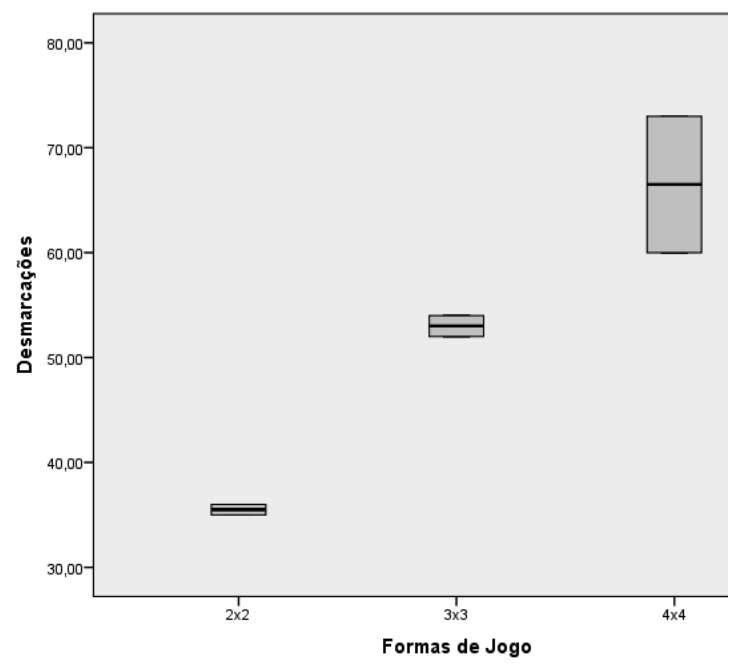

FIGURA 7 - Marcações individuais defensiva e desmarcações ofensiva.

Considerando o indicador desmarcações verificaram-se diferenças estatisticamente significativas, com efeito elevado $\left(F_{(2,3)}=16,661\right.$; "p-value" = 0,024; "Effect Size" = 0,917). Especificamente, constata-se que a maior frequência média surge na forma de jogo 4 x 4 sendo que, o inverso sucede na forma de jogo $2 \times 2$, diferenciando-se entre si ("p-value" =0,024). 


\section{Discussão}

Um dos aspetos determinantes para a implementação de uma tarefa relaciona-se diretamente com o que a mesma oferece aos praticantes. Nesse sentido, este estudo analisou a influência do número de alunos por jogo reduzido no que às açôes técnico/táticas se refere.

\section{Indicadores técnicos}

O contato e intervenção dos alunos sobre a bola é uma das preocupações centrais no processo de ensino. Recorrendo às formas de jogo 4 x 4 e 8 × 8 no futebol, Jones e DRUST ${ }^{16}$ verificaram diferenças estatisticamente significativas no que se refere ao número de contatos com a bola por jogador. Efetivamente, os resultados indicaram que o menor número de jogadores aumenta os contatos médios individuais com a bola. Em linha com o referido estudo encontra-se o presente trabalho desenvolvido no handebol onde, apesar de no cômputo geral existir uma frequência superior de contatos na bola na forma de jogo $4 \mathrm{x}$ 4 (a forma de jogo analisada com maior número de alunos), individualmente em média os alunos contatam inferiormente com a bola comparativamente às restantes formas de jogo analisadas $(2 \times 2$ e $3 \times 3)$. Em formas de jogo reduzidas a intervenção e ação individual é determinante para o sucesso coletivo. Aumentando o número de alunos e formas de jogo, a preponderância individual, bem como, a intervenção reduzirá progressivamente. Sugere-se portanto que, as formas de jogo alteram a estratégia e comportamentos táticos por parte dos praticantes, podendo constranger as ações individuais dos jogadores e, por conseguinte, a sua influência no jogo ${ }^{16}$. Igualmente ainda é possível sugerir que, o fato de globalmente a frequência de contatos na bola ser maior na forma de jogo superior, poderá relacionar-se com a complexidade do jogo, sendo que, as marcaçóes providenciadas, bem como, o reduzido espaço, induzem a maior frequência de intervençóes coletivas ofensivas procurando explorar a oportunidade de penetrar no bloco defensivo através de princípios táticos referentes a amplitude, bem como, profundidade.

Através do estudo de Platt et al. ${ }^{17}$ foi possível analisar que em jovens praticantes, a forma de jogo $3 \times 3$ concede mais oportunidades para realizar açôes como o drible, passe ou remate do que na forma de jogo $5 \times 5$. Semelhante constataçáo é realizada no estudo de Katis e Kellis ${ }^{18}$, onde analisaram as formas de jogo $3 \times 3$ e $6 \times 6$. De forma semelhante aos contatos com a bola, tais evidências são constatadas através da frequência média individual. No caso do presente trabalho em handebol, globalmente, é na forma de jogo $4 \times 4$ (i.e., forma de jogo com maior número de alunos) que ocorre a maior frequência de dribles e fintas. No entanto, analisando a média de frequência pelo número de alunos participantes, constata-se que é na forma de jogo 2 x 2 que sucede a maior frequência média de eventos relacionados com o drible e fintas. Tal fato poder-se-á justificar pela menor pressão exercida pela equipe adversária, designadamente, pela concretização da cobertura defensiva, criando oportunidades ao aluno com posse de bola de procurar desequilibrar a díade atacante-defensor.

No que se refere à frequência de gols ou pontos marcados, o estudo de Katis e Kellis ${ }^{18}$ revela que o maior número acontece nas formas de jogo mais reduzidas, comparando as formas de jogo $3 \times 3$ e 6 x 6 no futebol. Semelhante constataçáo é observada no presente trabalho em handebol onde, na forma de jogo 2 × 2 ocorre a maior frequência de pontos concretizados. Tal evidência poderá ser justificada pelo maior espaço existente para concretizar a ação sendo que, a menor concentração defensiva, garante a concretização de açóes ofensivas com maior proficuidade.

No que se refere às açôes técnicas de passe, estudos apresentam uma maior frequência de execução em formas de jogo mais reduzidas ${ }^{14,18}$. No entanto, no presente estudo verificou-se que o maior número de passes efetuados residiu na forma de jogo $3 \times 3$ sendo que o oposto sucedeu na forma de jogo $2 \mathrm{x}$ 2. Quanto ao maior número de passes completados verificou-se a permanência na forma de jogo $3 \times 3$ sendo que a maior frequência de passes incompletos ocorreu na forma de jogo 4 x 4 .

Assim, será necessário atender a aspectos táticos no sentido de justificar as evidências advindas dos resultados. Considera-se que o maior número de passes incompletos na forma de jogo $4 \mathrm{x} 4$ poderse-á dever à maior pressão efetuada pelos alunos em fase defensiva. Efetivamente os dados demonstram que o maior número de marcaçóes sucedeu nesta forma de jogo, pelo que, a pressão exercida poderá relacionar-se com o incremento de passes incompletos provocados pela antecipação e desarmes defensivos. Inversamente o menor número de passes incompletos sucede na forma de jogo de $2 \times 2$ onde o espaço é maior e a pressão sobre o portador de bola menor, possibilitando que a eficácia do passe decorra com maior proficuidade. 
Quanto à frequência de passes completados, importa salientar que reside na forma de jogo $3 \mathrm{x}$ 3 a maior. Efetivamente tal fato poderá justificar-se pela triangulação ofensiva constituída pelos alunos, garantindo mais opçóes de deliberação ofensiva relativamente ao 2 × 2 e menos pressão defensiva adversária do que no $4 \times 4$. No fundo, considera-se o $3 \times 3$ uma forma de jogo passível de permitir a consecução eficaz de conteúdos técnicos relacionados com o passe, procurando explorar a profundidade e a amplitude do espaço ofensivo através dos dois companheiros em desmarcação.

No que se refere à tipologia de passes será importante analisar a adequação a cada forma de jogo. Efetivamente o passe picado efetuou-se com maior frequência na forma de jogo $2 \times 2$. Quanto ao indicador passe de ombro denotou-se a maior frequência na forma de jogo $4 \times 4$. No que se refere a outros tipos de passes assistiu-se à maior recorrência na forma de jogo $3 \times 3$. De fato, o tipo de passe poder-se-á relacionar com a ação coletiva da equipe. Efetivamente verifica-se que no caso das formas de jogo com maior número de alunos, existe maior número de desmarcações e marcaçóes. Consequentemente, os passes de ombro e outros tipos de passe poderão ser um indicador da necessidade de explorar o adversário através da amplitude e profundidade.

Importa enfatizar que as formas de jogo selecionadas, simultaneamente aos efeitos induzidos nas açôes técnicas, constituem-se como uma variável determinante para a consecuçáo de comportamentos táticos. Igualmente, importa considerar que cada forma de jogo favorece a consecução de determinado envolvimento coletivo, pelo que, afigura-se pertinente analisar as possibilidades que cada uma origina.

\section{Indicadores táticos}

No que se refere à frequência de ataques importa destacar o contributo da forma de jogo $3 \times 3 \mathrm{em}$ favor da origem deste tipo de açôes. Efetivamente é na forma de jogo $3 \times 3$ que sucede a maior frequência de açôes de ataque, bem como, de ataques organizados. $\mathrm{O}$ fato de existir maior frequência de alunos no mesmo espaço condicionará a celeridade do processo ofensivo devido à redução de possibilidades de tomada de decisão constrangidas pela marcação dos oponentes, incrementando o tempo de organizaçáo ofensiva.

No que se refere ao contra-ataque importa salientar que a forma de jogo $2 \times 2$ se diferencia estatisticamente pela superior frequência de açôes ofensivas deste tipo. Tal fato poder-se-á justificar pelo menor equilíbrio defensivo originado pelo menor número de alunos, pelo que, aquando das transições defesaataque a possibilidade de explorar os adversários será maior incrementando, consequentemente, a celeridade na consecução do processo ofensivo. Igualmente importa enfatizar que na forma de jogo $2 \times 2$ existe a maior origem de pontos concretizados pelas equipes, pelo que, a mesma favorecerá a opção por recorrer a comportamentos de desmarcação em rutura potenciando as oportunidades originadas pelo desequilíbrio defensivo adversário. Adicionalmente afigura-se pertinente referir que na mesma forma de jogo (i.e., $2 \times 2$ ) a eficácia do contraataque é superior diferenciando-se estatisticamente, possivelmente potenciada pelo menor número de opositores, acrescentando possibilidades de sucesso à organizaçáo ofensiva.

Sumariamente, no que concerne às formas de jogo, será importante enfatizar que o menor número de alunos incrementa significativamente as oportunidades de recorrer ao contra-ataque, possibilitado pelo menor número de opositores, bem como, pelo maior desequilíbrio defensivo desencadeado pela transição defesa-ataque. Nesse sentido, as movimentações ofensivas poderão ser superiormente abrangentes e imprevisíveis existindo mais espaço para explorar os desequilíbrios defensivos adversários, reduzindo as possibilidades de sucesso dos defensores. Inversamente, a forma de jogo $3 \times 3$ incrementa as açóes de ataque organizado possibilitando a maior percepçáo dos alunos quanto à consecução deste tipo de açáo ofensiva. Efetivamente, o fato de existirem mais defensores reduz a possibilidade de agir de forma célere (i.e., contra-ataque, ataque rápido), despoletando a necessidade de organizar qualitativamente o ataque. No caso da forma de jogo $4 \times 4$, o fato de existirem mais defensores no mesmo espaço de prática, incrementa o tempo do ataque, reduzindo a frequência do mesmo. Salvaguarde-se, no entanto, que o fato de existirem mais alunos em prática, possibilita o incremento de açôes de desmarcação e marcaçôes individuais favorecendo a necessidade de os alunos explorarem o meio em favor do sucesso interventivo.

No fundo, as formas de jogo com maior número de alunos poderão ser importantes para a consolidação de ações dinâmicas sistemáticas no sentido de incrementar os princípios de jogo de mobilidade, concedendo maior complexidade tática cognitiva aos alunos e potenciando, dessa forma, a necessidade de percecionarem o meio em funçáo dos problemas existentes explorando as possibilidades pontuais e, 
consequentemente, concedendo-lhes oportunidade de acelerarem o processo de tomada de decisão.

Concluindo, o presente trabalho objetivou analisar os efeitos do número de participantes na exercitação de formas de jogo reduzidos, procurando percecionar os efeitos no que à consecução técnica e tática se refere.

Os resultados denotam diferenças entre as formas de jogo observadas em indicadores técnicos e táticos, comprovando-se a pertinência dos mesmos no que concerne à dinamização dos jogos reduzidos. Efetivamente importa enfatizar que a manipulação do número de alunos será uma variável impreterível no momento de dinamizar as atividades atendendo aos seus efeitos na aprendizagem e desenvolvimento de conteúdos técnicos e táticos.

De fato, será expectável que para alunos com menor nível de proficiência se opte pela redução das formas de jogo no sentido de aumentar as açóes técnicas e tática realizadas por cada aluno. Posteriormente, em níveis de proficiência superiores, será importante aumentar o número de jogadores por jogo no sentido de incrementar a complexidade das açóes técnicas e táticas, conferindo maior realismo dinâmico relativamente à modalidade abordada.

\begin{abstract}
The influence of number of players on small-sided handball games: changing on technical and tactical dynamic

The aim of this study was to verity the effects of different formats of handball game ( 2 vs 2,3 vs 3 and 4 vs 4 ) on technical and tactical performance of Physical Education students. Eight male students (18.25 \pm 1.04 years old) participated in this study. It was possible to verify significant statistical differences in the number of ball contacts, number of shoulder passes and shoulder passes completed. It was also possible to verify significant statistical differences in the organized attack and counterattack. Therefore, it was possible to conclude that smaller formats of small-sided handball games allows to increase the technical and tactical actions, thus being more appropriated to early stages of learning.
\end{abstract}

KEY woRDS: Teaching; Physical education; Small-sided games; Handball.

\title{
Referências
}

1. Clemente F, Mendes R. Aprender o jogo jogando: uma abordagem transdisciplinar. Rev Cient Exedra. 2011;5:27-36.

2. Clemente F, Couceiro MS, Martins FML, Mendes R. The usefulness of small-sided games on soccer training. J Phys Educ Sport. 2012;12:93-102.

3. Turner A, Martinek TJ. An investigation into teaching games for understanding: effects on skill, knowledge, and game play. Res Q Exerc Sport. 1999;70:286-96.

4. Araújo D. Tomada de decisão no desporto. Cruz Quebrada: FMH Ediçóes; 2006.

5. Chow JY, Davids K, Button C, Shuttleworth R, Renshaw I, Araújo D. Nonlinear pedagogy: a constraints-led framework to understand emergence of game play and skills. Nonlinear Dynamics Psychol Life Sci. 2006;10:71-104.

6. Bunker D, Thorpe R. From theory to practice. In: Thorpe R, Bunker D, Almond L, organizers. Rethinking games teaching. Loughborough: University of Technology; 1986. p.11-6.

7. Renshaw I, Chow JY, Davids K, Hammond J. A constraints-led perspective to understanding skill acquisition and game play: a basis for integration of motor learning theory and physical education praxis? Phys Educ Sport Pedagog. 2010;15:117-37.

8. Newell KM. Constraints on the development of coordination. In: Wade MG, Whiting HTA, organizers. Motor development in children: aspects of coordination and control. Dordrecht: Martinus Nijhoff: 1986. p.341-60.

9. Tessitore A, Meeusen R, Piacentini MF, Demarie S, Capranica L. Physiological and technical aspects of "6-a-side” soccer drills. J Sports Med Phys Fitness. 2006;46:36-43.

10. Rampinini E, Impellizzeri FM, Castagna C, et al. Factors influencing physiological responses to small-sided soccer games. J Sports Sci. 2007;25:659-66. 
11. Hill-Haas SV, Dawson BT, Coutts AJ, Rowsell GJ. Physiological responses and time-motion characteristics of various small-sided soccer games in youth players. J Sports Sci. 2009;27:1-8.

12. Casamichana D, Castellano J. Time-motion, heart rate, perceptual and motor behaviour demands in small-sides soccer games: effects of field size. J Sports Sci. 2010;28:1615-23.

13. Owen A, Twist C, Ford P. Small-sided games: the physiological and technical effect of altering field size and player numbers. Insight. 2004;7:50-3.

14. Rudolf P, Václav B. Heart rate response and game-related activity of younger school-age boys in different formats of soccer game. Ovidius U Ann: Series Phys Educ Sport/Sci Movement Health. 2009;1:69-73.

15. Hopkins KD, Hopkins BR, Glass GV. Basic statistics for the behavioral sciences. Boston: Allyn and Bacon; 1996.

16. Jones S, Drust B. Physiological and technical demands of $4 \mathrm{v} 4$ and 8 v 8 games in elite youth soccer players. Kinesiology. 2007;39:150-6.

17. Platt D, Maxwell A, Horn R, Williams M, Reilly T. Physiological and technical analysis of 3 v 3 and 5 v 5 youth football matches. Insight. 2001;4:23-4.

18. Katis A, Kellis E. Effects of small-sided games on physical conditioning and performance in young soccer players. J Sports Sci Med. 2009;8:374-80.

ENDEREÇO

Filipe Manuel Clemente

Instituto Politécnico de Coimbra

Escola Superior de Educação de Coimbra

R. Dom João III - Solum

3030-329 - Coimbra - PORTUGAL

e-mail: filipe.clemente5@gmail.com
Recebido para publicação: 05/06/2012

1a. Revisão: 17/07/2013

2a. Revisão: 25/09/2013

Aceito: 20/01/2014 